\title{
Limit Sets and Cartan D - space
}

\section{Habeeb Kareem Abdulla \\ University of Kufa \\ College of Education for Girls \\ Department of Mathematics}

Habeebk.abdullah@uokufa.edu.iq

Recived : $24 \backslash 8 \backslash 2017$
Haider Jebur Ali

Al Mustansiriyah University

College Of Science

Department of Mathematics

Haiderali@yahoo.com

Revised : 20\9\2017
Ahmed Talip Hussein

Al Mustansiriyah University College of Computer Science and

Information Technology

Department of Mathematics

Ahmed.talip@qu.edu.iq

Accepted : 19\10\2017

\begin{abstract}
:
The main goal of this work is to create a general type of D - space, namely, Cartan D - space and a new type of limit sets, namely, limit sets $\Lambda(x), J(x)$ and, give some properties and some equivalent statement of these concept also we explain the relationship among the definitions Cartan D - space and $\Lambda(x), J(x)$
\end{abstract}

\section{Mathematics Subject Classification 2010:51H05}

\section{Introduction:}

Y. I m a i and K. I s e $\mathrm{k}$ i [4] and K. I s e k i [5] introduced two classes of abstract algebras: namely, BCK-algebras and BCI-algebras. It is known that the class of BCK algebras is a proper subclass of the class of BCI-algebras. In [2], [3] Q. P. Hu and X. Li introduced a wide class of abstract algebras: $\mathrm{BCH}$-algebras. They have shown that the class of BCI-algebras is a proper subclass of the class of $\mathrm{BCH}$-algebras. J. N e g g e r s and H. S. K i m [6] introduced the notion of $\mathrm{d}$-algebras which is another generalization of BCK-algebras, and investigated relations between d-algebras and BCK-algebras. They studied the various topologies in a manner analogous to the study of lattices. However, no attempts have been made to study the topological structures making the star operation of $d-$ algebra continuous. Theories of topological groups, topological rings and topological modules are well known and still investigated by many mathematicians. Even topological universal algebraic structures have been studied by some authors. In section one we initiate the study of topological d - algebras. We need some preliminary materials that are necessary for the development of the paper. In section two, we define the sets $\Lambda(x), J(x)$ and prove its properties, also we give some equivalent statement of $\Lambda(x), J(x)$.In section three, we defines thin sets and Cartan D - space and give some propositions and theorems which related with this concepts and shown the relationship among the Cartan D - space and the sets $\Lambda(x)$ and $J(x)$.

\section{Preliminaries}

1.1Definition: A non-empty set $\mathrm{X}$ together with a binary operation $*$ and a zero element 0 is said to be a d - algebra if the following axioms are satisfied for all $\mathrm{x}, \mathrm{y} \in \mathrm{X}$

1)) $x * x=0$

2) $0 * x=0$

3) $\mathrm{x} * \mathrm{y}=0$ and $\mathrm{y} * \mathrm{x}=0$ imply that $\mathrm{x}=\mathrm{y}$.

1.2 Definition: An element e of $\mathrm{D}$ is called a left identity if $\mathrm{e}^{*} \mathrm{a}=\mathrm{a}$, a right identity if $\mathrm{a}^{*} \mathrm{e}=\mathrm{a}$ for all $\mathrm{a} \in \mathrm{D}$ and $\mathrm{a} \neq \mathrm{e}$. If $\mathrm{e}$ is both left and right identity then we called e is an identity element.

\subsection{Example:}

i) Let $\mathrm{D}$ be any non - empty set and $\mathrm{P}(\mathrm{D})$ is power set of $D$ then $(P(D),-)$ is $d-$ algebra and $\phi$ is right identity in $(\mathrm{P}(\mathrm{D}),-$ ).

ii) let $\mathrm{D}=\{0, \mathrm{a}, \mathrm{b}, \mathrm{c}\}$ and define the binary operation * on $\mathrm{D}$ by the following table: 


\begin{tabular}{|c|c|c|c|c|}
\hline$*$ & 0 & $\mathrm{a}$ & $\mathrm{b}$ & $\mathrm{c}$ \\
\hline 0 & 0 & 0 & 0 & 0 \\
\hline $\mathrm{a}$ & $\mathrm{a}$ & 0 & 0 & $\mathrm{a}$ \\
\hline $\mathrm{b}$ & $\mathrm{b}$ & $\mathrm{b}$ & 0 & $\mathrm{~b}$ \\
\hline $\mathrm{c}$ & $\mathrm{c}$ & $\mathrm{c}$ & $\mathrm{C}$ & 0 \\
\hline
\end{tabular}

Then it is clear that the pair $\left(\mathrm{D},{ }^{*}\right)$ is $\mathrm{d}$ - algebra with identity element.

1.4 Definition : Let $\left(D,{ }^{*}\right)$ be a $d-$ algebra and $\mathrm{T}$ be a topology on $\mathrm{D}$. The triple $\left(\mathrm{D},{ }^{*}, \mathrm{~T}\right)$ is called a topological $\mathrm{d}$ - algebra (denoted by $\mathrm{Td}-$ algebra) if the binary operation $*$ is continuous.

\subsection{Example:}

i) Let $\mathrm{D}=\{0, \mathrm{a}, \mathrm{b}, \mathrm{c}\}$ and $*$ be define by the following table:

\begin{tabular}{|c|c|c|c|c|}
\hline$*$ & 0 & $\mathrm{a}$ & $\mathrm{b}$ & $\mathrm{c}$ \\
\hline 0 & 0 & 0 & 0 & 0 \\
\hline $\mathrm{a}$ & 0 & 0 & $\mathrm{~b}$ & $\mathrm{c}$ \\
\hline $\mathrm{b}$ & 0 & $\mathrm{~b}$ & 0 & $\mathrm{a}$ \\
\hline $\mathrm{c}$ & 0 & $\mathrm{c}$ & $\mathrm{a}$ & 0 \\
\hline
\end{tabular}

It is clear that $\left(\mathrm{D},{ }^{*}\right)$ is $\mathrm{d}-$ algebra and $\mathrm{T}=\{\phi,\{\mathrm{b}\},\{\mathrm{c}\},\{0, \mathrm{a}\},\{\mathrm{b}, \mathrm{c}\},\{0, \mathrm{a}, \mathrm{b}\},\{0, \mathrm{a}, \mathrm{c}\}, \mathrm{D}\}$ is a topology on $\mathrm{D}$ such that the triple $\left(\mathrm{D},{ }^{*}, \mathrm{~T}\right)$ is a topological d - algebra.

ii) Let $\mathrm{R}$ be a set of real number and * is a binary operation which define by $\mathrm{a} * \mathrm{~b}=$ a. $(\mathrm{a}-\mathrm{b})$ then $\left(\mathrm{R},{ }^{*}, \mathrm{~T}\right)$ is $\mathrm{Td}$ - algebra where $\mathrm{T}$ is the usual topology on $\mathrm{R}$.

1.7Definition: A topological transformation $\mathrm{d}$ - algebra is a triple $(\mathrm{D}, \mathrm{X}, \varphi)$ where $\mathrm{D}$ is a topological $\mathrm{d}-$ algebra, $X$ is a topological space and $\varphi: D \times X \rightarrow X$ is a continuous function such that $\varphi\left(d_{1}, \varphi\left(d_{2}, x\right)\right)=\varphi\left(d_{1} d_{2}, x\right)$ for all $\mathrm{d}_{1} \neq \mathrm{d}_{2}$ and $\mathrm{d}_{1}, \mathrm{~d}_{2} \in \mathrm{D}, \mathrm{x} \in \mathrm{X}$, and if $(\mathrm{D}, *)$ is a topological $d$ - algebra with identity, we say that the triple $(D, X, \varphi)$ is a topological transformation $\mathrm{d}-$ algebra with identity if $\varphi(e, x)=x$ for all $x \in X$, where $\mathrm{e}$ is the identity element of $\mathrm{D}$.

1.8 Example: Let $(\mathrm{R}, *, \mathrm{U})$ be a $\mathrm{Td}$ - algebra, where $a * b=a(a-b)$ for all $a, b \in R$ and $(R, U)$ is the usual space. Then $(R, R, \varphi)$ is a topological transformation $\mathrm{d}$ - algebra where $\varphi(a, b)=b$ for all $a, b \in R$.

\subsection{Remark:}

(i) The function $\varphi$ is called an action of $\mathrm{D}$ on $\mathrm{X}$ and the space $X$ together with $\varphi$ is called a D - space ( or more precisely left D space ) and if $(\mathrm{D}, *)$ is a topological $\mathrm{d}-$ algebra with identity the space $X$ together with $\varphi$, then $(\mathrm{D}, *)$ is called a $\mathrm{D}$ - space with identity.

(ii) Since $\varphi$ is understood from the context we shall often use the notation d.x for $\varphi(d, x)$ and $d_{1} \cdot\left(d_{2} \cdot x\right)=\left(d_{1} d_{2}\right) \cdot x$ for $\varphi\left(d_{1}, \varphi\left(d_{2}, x\right)\right)$ $=\varphi\left(\mathrm{d}_{1} \mathrm{~d}_{2}, \mathrm{x}\right)$.

(iii) Similarly, for $\mathrm{H} \subseteq \mathrm{D}$ and $\mathrm{A} \subseteq \mathrm{X}$ we put $\mathrm{HA}=\{\mathrm{da} / \mathrm{d} \in \mathrm{H}, \mathrm{a} \in \mathrm{A}\}$ for $\varphi(\mathrm{H}, \mathrm{A})$.

(iv) For $d \in D$, let $\varphi_{d}: X \rightarrow X$ be the continuous function defined by $\varphi_{\mathrm{d}}(\mathrm{x})=\varphi(\mathrm{d}, \mathrm{x})$

$=\mathrm{d}$.x . Thus $\varphi_{d_{1}} \varphi_{d_{2}}=\varphi_{d_{1} d_{2}}$ and if $\mathrm{X}$ is $\mathrm{D}-$ space with identity then $\varphi_{e}=I_{X}$, the identity function of $X$.

\section{2 - limit sets of a point:}

From now on, in this section by $\mathrm{D}$ - space is meant a completely regular topological $T_{2}-$ space $\mathrm{X}$ on which an locally compact, non compact, $\mathrm{T}_{2}$ - topological $\mathrm{d}-$ algebra $\mathrm{D}$ with right identity 0 (where 0 is zero element in $\mathrm{D}$ ) acts continuously on the left.

2.1 Definition: Let $X$ be a $D$ - space and $x \in X$. Then:

(i) $\Lambda(x)=\left\{y \in X\right.$ : there is a net $\left(d_{g}\right)_{g \in G}$ in $D$ with $\mathrm{d}_{\mathrm{g}} \longrightarrow \infty$ such that $\mathrm{d}_{\mathrm{g}} \mathrm{x} \longrightarrow \mathrm{y}$ \} is called limit set of $\mathrm{x}$.

(ii) $J(x)=\left\{\mathrm{y} \in \mathrm{X}\right.$ : there is a net $\left(\mathrm{d}_{\mathrm{g}}\right)_{\mathrm{g} \in \mathrm{G}}$ in $\mathrm{D}$ and there is a net $\left(\chi_{d}\right)_{d \in D}$ in $X$ with $d_{g}$ $\longrightarrow \infty$ and $\chi_{\mathrm{d}} \longrightarrow \mathrm{x}$ such that $\mathrm{d}_{\mathrm{g}} \mathrm{x}$ $\longrightarrow \mathrm{y}\}$ is called first prolongation limit set of $x$.

2.2 Proposition: Let $X$ be a $D$ - space and $\mathrm{x} \in \mathrm{X}$. Then:

(i) The orbit Dx is closed if and only if $\Lambda(x)$ is a subset of Dx.

(ii) If $\mathrm{x} \notin \Lambda(x)$, then the stabilizer $\mathrm{d}-\mathrm{sub}$ algebra $\mathrm{D}_{\mathrm{x}}$ of $\mathrm{D}$ is compact.

(iii) if $\Lambda(x)=\phi$, for each $\mathrm{x} \in \mathrm{X}$. Then the orbit Dx is not compact.

(iv) $\overline{D x}=\mathrm{Dx} \cup \Lambda(x)$

(v) If $\mathrm{X}$ is discrete $\mathrm{G}$ - space, then $\Lambda(x)=$ $J(x)$ for each $\mathrm{x} \in \mathrm{X}$. 


\section{Proof:}

i) $\Rightarrow$ Let $y \in \Lambda(x)$, then there is a net $\left(d_{g}\right)_{g \in G}$ in $\mathrm{D}$ such that $\mathrm{d}_{\mathrm{g}} \longrightarrow \infty$ and $\mathrm{d}_{\mathrm{g}} \mathrm{x} \longrightarrow \mathrm{y}$. Since $d_{g} x \in D x$ and $\left(d_{g} x\right)_{g \in G}$ is a net in $D x$, then by Proposition (1.8) ye $\overline{D x}$. But Dx is closed then $\mathrm{y} \in \mathrm{Dx}$ so $\Lambda(x) \subseteq \mathrm{Dx}$.

$\Leftarrow$ Let $\mathrm{y} \in \overline{\boldsymbol{D x}}$. Then there exists $\left(\mathrm{y}_{\mathrm{g}}\right)_{\mathrm{g} \in \mathrm{G}}$ is a net in Dx such that $\mathrm{y}_{\mathrm{g}} \longrightarrow \mathrm{y}$, then $\forall \mathrm{g} \in \mathrm{G}$ there is $d_{g} \in D$ such that $y_{g}=d_{g} x$. Then $\left(d_{g}\right)_{g \in G}$ is a net in $D$ and $d_{g} x \longrightarrow y$. Now either $d_{g}$ $\longrightarrow \mathrm{d}$ or $\mathrm{d}_{\mathrm{g}} \longrightarrow \infty$. If $\mathrm{d}_{\mathrm{g}} \longrightarrow \mathrm{d}$ then $\mathrm{d}_{\mathrm{g}} \mathrm{x}$ $\longrightarrow \mathrm{dx}=\mathrm{y}$, which implies that $\mathrm{y} \in \mathrm{Dx}$. If $\mathrm{d}_{\mathrm{g}}$ $\longrightarrow \infty$, then $\mathrm{y} \in \Lambda(x) \subseteq \mathrm{Dx}$, then $\mathrm{Dx}$ is closed.

(ii) Let $\mathrm{x} \notin \Lambda(x)$ and suppose that $\mathrm{D}_{\mathrm{x}}$ is not compact. Then there is a net $\left(d_{g}\right)_{g \in G}$ in $G$ such that $d_{g} \longrightarrow \infty$. Since $d_{g} x=x$, i.e. $d_{g} x$ $\longrightarrow \mathrm{x}$ then $\mathrm{x} \in \Lambda(x)$ which is a contradiction, thus $\mathrm{D}_{\mathrm{x}}$ is compact.

(iii) Suppose that Dx is compact. Since D is not compact, then there is a net $\left(\mathrm{d}_{\mathrm{g}}\right)_{\mathrm{g} \in \mathrm{G}}$ in $\mathrm{D}$ with $d_{g} \longrightarrow \infty$, . But Dx is compact and $\left(d_{\mathrm{g}} \mathrm{x}\right)$ $\mathrm{g} \in \mathrm{G}$ is a net in Dx then by Proposition (1.7) $\mathrm{d}_{\mathrm{g}} \mathrm{x}$ $\longrightarrow \mathrm{y}$ for some $\mathrm{y} \in \mathrm{X}$. Hence $\mathrm{y} \in \Lambda(x)$, which is a contradiction with $\Lambda(x)=\phi$.

(iv) The proof of (iv) is obvious.

(v) The proof of (v) is obvious.

2.3 Proposition: Let $X$ be an $\mathrm{D}$ - space and $\mathrm{x} \in \mathrm{X}$. Then $\mathrm{x} \notin \Lambda(x)$ if and only if there is a neighborhood $U$ of $x$ and a compact neighborhood $\mathrm{V}$ of 0,0 is the right identity in $\mathrm{D}$, such that $\mathrm{dx} \notin \mathrm{U}$ for each $\mathrm{d} \notin \mathrm{V}$.

Proof: Let $\mathrm{x} \notin \Lambda(x)$ and suppose that the resulting statement is not true. i.e. for each neighborhood $\mathrm{U}$ of $\mathrm{x}$ and for each compact neighborhood $\mathrm{V}$ of 0 , there is point $\mathrm{d} \notin \mathrm{V}$ and $\mathrm{dx} \in \mathrm{U}$. Since $\mathrm{X}$ is completely regular, then there is a sequence $\left\{\mathrm{U}_{\mathrm{n}}\right\}_{\mathrm{n} \in \mathrm{Z}^{+}}$of an open neighborhood of $\mathrm{x}$ such that $\mathrm{U}_{\mathrm{n}+1} \subset \mathrm{U}_{\mathrm{n}} \subseteq \ldots$ and

$$
\bigcap_{n \in Z^{+}} U_{n}=\{x\} \text {. Since } \mathrm{x} \notin \Lambda(x) \text {, }
$$

then by Proposition(2.2,ii) $\mathrm{D}_{\mathrm{x}}$ is compact. Since D is locally compact. Then there is a compact neighborhood $\mathrm{V}$ of e such that $\mathrm{D}_{\mathrm{x}} \subseteq$ $V$. Thus for each $n$, there is $d_{n} \notin V$ and $d_{n} x$ $\longrightarrow \mathrm{x}$. By the hypothesis $\mathrm{x} \notin \Lambda(x)$, then $\left(d_{n}\right)_{n \in N}$ has an convergent subnet of $\left(d_{n}\right)_{n \in N}$. Say itself. i.e. there is $d \in D$ such that $\mathrm{d}_{\mathrm{n}} \longrightarrow \mathrm{d}$, and hence $\mathrm{d}_{\mathrm{n}} \mathrm{x} \longrightarrow \mathrm{dx}=\mathrm{x}$ which means

that $\mathrm{d} \in \mathrm{D}_{\mathrm{x}} \subseteq \mathrm{V}$ thus for $\mathrm{n}_{\mathrm{o}} \in \mathrm{N}, \mathrm{d}_{\mathrm{n}} \in \mathrm{V}$ for each $n \geq n_{0}$, which contradiction that $d_{n} \notin V$, therefore that the statement is true.

Conversely: Let the statement be true. We suppose that $\mathrm{x} \in \Lambda(x)$ then there is a net $\left(\mathrm{d}_{\mathrm{g}}\right)_{\mathrm{g} \in \mathrm{G}}$ in $\mathrm{D}$ such that $\mathrm{d}_{\mathrm{g}} \longrightarrow \infty$ and $\mathrm{d}_{\mathrm{g}} \mathrm{x}$ $\longrightarrow \mathrm{x}$, by hypothesis there exists $U$ be a neighborhood of $x$ and a compact neighborhood of 0 such that $\mathrm{dx} \notin \mathrm{U}$ for each $\mathrm{d} \notin \mathrm{V}$. Since $\mathrm{d}_{\mathrm{g}} \mathrm{x} \longrightarrow \mathrm{x}$ then there is $\mathrm{g}_{\mathrm{o}} \in \mathrm{G}$ such that $d_{g} x \in U$, for each $g \geq g_{0}$, therefore that $\mathrm{d}_{\mathrm{g}} \in \mathrm{V}$, which is an compact, thus the net $\left(d_{g}\right)_{g \in G}$ has an convergent sub net, say itself, i.e., there is a point $d \in D$ such that $d_{g} \longrightarrow d$ which is contradiction, since $\left(\mathrm{d}_{\mathrm{g}}\right)_{\mathrm{g} \in \mathrm{G}}$ has no convergent sub net, thus $\mathrm{x} \notin \Lambda(x)$

2.4 Notation: Let $X$ be a D - space and A, B be two subset of $X$. We mean by $((A, B))$ the set $\{\mathrm{d} \in \mathrm{D} / \mathrm{dA} \cap \mathrm{B} \neq \phi\}$.

2.5 Proposition: Let $X$ be an $\mathrm{D}$ - space and $\mathrm{X}$, $y \in X$. If there is a neighborhood $U$ of $y$ and a compact neighborhood $\mathrm{V}$ of 0 , such that $\mathrm{dx} \notin \mathrm{U}$ for each $\mathrm{d} \notin \mathrm{V}$, then $\mathrm{y} \notin \Lambda(x)$.

\section{Proof:}

Suppose that $\mathrm{y} \in \Lambda(x)$, then there is a net $\left(d_{g}\right)_{g \in G}$ in D with $d_{g} \longrightarrow \infty$ such that $d_{g} x$ $\longrightarrow y$. Then by hypothesis there is a neighborhood $U$ of $y$ and compact neighborhood $\mathrm{V}$ of 0 , such that $\mathrm{d}_{\mathrm{g}} \mathrm{x} \notin \mathrm{U}$ for each $\mathrm{d} \notin \mathrm{V}$. Since $\mathrm{d}_{\mathrm{g}} \mathrm{x} \longrightarrow \mathrm{y}$, then there is $\mathrm{g}_{\mathrm{o}} \in \mathrm{D}$ such that $d_{g} x \in U$ for each $g_{o} \geq g$, therefore $\mathrm{d}_{\mathrm{g}} \in \mathrm{V}$, which is compact, then $\left(\mathrm{d}_{\mathrm{g}}\right)_{\mathrm{g} \in \mathrm{G}}$ has a convergent subnet, which contradictions that $\mathrm{d}_{\mathrm{g}}$ $\longrightarrow \infty$. Hence $\mathrm{y} \notin \Lambda(x)$.

2.6 Theorem: Let $X$ be $\mathrm{D}$ - space and $\mathrm{x} \in \mathrm{X}$. Then $\mathrm{x} \notin J(x)$ if and only if there is a neighborhood $U$ of $x$ and there is a neighborhood $\mathrm{V}$ of 0 , where 0 is the right identity element of $\mathrm{D}$, such that $\mathrm{dU} \cap \mathrm{U}=\phi$ for each $\mathrm{d} \notin \mathrm{V}$. 
Proof: $\Rightarrow$ We suppose that the above statement is not true, i.e., for each neighborhood $\mathrm{U}$ of $\mathrm{x}$ and for each compact neighborhood $\mathrm{V}$ of 0 there is $\mathrm{d} \notin \mathrm{V}$ such that $\mathrm{dU} \cap \mathrm{U} \neq \phi$. We can choose $\left\{U_{n}\right\}_{n \in Z^{+}}$to be sequence of an open neighborhood of $\mathrm{x}$ such that $\mathrm{U}_{\mathrm{n}+1} \subset \mathrm{U}_{\mathrm{n}} \subset \ldots$ and $\bigcap_{n \in Z^{+}} U_{n}=\{x\}$. Since $\mathrm{D}$ is locally compact, then there is a compact neighborhood of 0 , such that $\mathrm{D}_{\mathrm{x}} \subset \mathrm{V}$. Thus for each $n$ there is $d_{n} \notin V$ such that $d_{n} U_{n} \cap U_{n} \neq \phi$ i.e., there is $\chi_{n} \in U_{n}$ and $d_{n} \chi_{n} \in U_{n}$. Since $\bigcap_{n \in Z^{+}} U_{n}=\{x\}$, then we have $\chi_{\mathrm{n}} \longrightarrow \mathrm{x}$, $\mathrm{d}_{\mathrm{n}} \chi_{\mathrm{n}} \longrightarrow \mathrm{x}$ and by hypothesis the sequence $\left(d_{n}\right)_{n \in N}$ has a convergent sub sequence, say itself, thus there is a point $d \in D$ such that $d_{n}$ $\longrightarrow \mathrm{d}$, and since the action is continuous. Then we get $d_{n} \chi_{n} \longrightarrow d x=x$ and hence $d \in$ $D_{x} \subset V$, therefore $d_{n} \in V$ for $n \geq n_{o}$, which is a contradiction. Thus the statement is true.

Conversely: $\Leftarrow$ Let the statement be true, we suppose that $\mathrm{x} \in J(x)$. Then there is a net $\left(\mathrm{d}_{\mathrm{g}}\right)_{\mathrm{g} \in \mathrm{G}}$ in $\mathrm{G}$ with $\mathrm{d}_{\mathrm{g}} \longrightarrow \infty$ and there is a net $\left(\chi_{\mathrm{g}}\right)_{\mathrm{g} \in \mathrm{G}}$ in $\mathrm{X}$ with $\chi_{\mathrm{g}} \longrightarrow \mathrm{x}$ such that $\mathrm{d}_{\mathrm{g}} \chi_{\mathrm{g}}$ $\longrightarrow \mathrm{x}$. Then by hypothesis, there exists $U$ be a neighborhood of $\mathrm{x}$ and $\mathrm{V}$ be an compact neighborhood of 0 such that $\mathrm{dU} \cap \mathrm{U}=\phi$ for each $d \notin V$. Since $\left(\chi_{g}\right)_{g \in G}$ and $\left(d_{g} \chi_{g}\right)_{g \in G}$ are convergent to $\mathrm{x}$, thus there is $\mathrm{g}_{\mathrm{o}} \in \mathrm{G}$ such that $\chi_{\mathrm{g}} \in \mathrm{U}$ and $\mathrm{d}_{\mathrm{g}} \chi_{\mathrm{g}} \in \mathrm{U}$ for each $\mathrm{g} \geq \mathrm{g}_{\mathrm{o}}$ and hence $\mathrm{d}_{\mathrm{g}}$ $\in((\mathrm{U}, \mathrm{U}))$, therefore $\mathrm{d}_{\mathrm{g}} \in \mathrm{V}$, which is compact , this it must have a convergent sub net which is a contradiction $\mathrm{x} \notin J \quad(x)$.

\section{3 -Cartan D - space}

3.1 Definition: Let $X$ be a $D$ - space .A subset $A$ of $X$ is said to be thin relative to a subset $B$ of $\mathrm{X}$ if the set $((\mathrm{A}, \mathrm{B}))=\{\mathrm{d} \in \mathrm{D} / \mathrm{dA} \cap \mathrm{B} \neq \phi\}$ has a neighborhood whose closure is compact in $\mathrm{D}$. If $\mathrm{A}$ is thin relative to itself, then it is called thin.

3.2 Remark: The thin sets have the following properties:

(i) If $\mathrm{A}$ and $\mathrm{B}$ are relative thin and $\mathrm{K}_{1} \subseteq \mathrm{A}$ and $\mathrm{K}_{2} \subseteq \mathrm{B}$, then $\mathrm{K}_{1}$ and $\mathrm{K}_{2}$ are relatively thin.

(ii) Let $\mathrm{X}$ be a $\mathrm{D}$ - space and $\mathrm{K}_{1}, \mathrm{~K}_{2}$ be compact subset of $\mathrm{X}$. Then $\left(\left(\mathrm{K}_{1}, \mathrm{~K}_{2}\right)\right)$ is closed in $\mathrm{D}$.

(iii) If $\mathrm{K}_{1}$ and $\mathrm{K}_{2}$ are compact subset of $\mathrm{D}$ space $X$ such that $K_{1}$ and $K_{2}$ are relatively thin, then $\left(\left(\mathrm{K}_{1}, \mathrm{~K}_{2}\right)\right)$ is a compact subset of $\mathrm{D}$.
Proof: The prove of (i) and (iii) are obvious.

(ii) Let $\mathrm{d} \in \overline{\left(\left(K_{1}, K_{2}\right)\right)}$. Then there is a net $\left(d_{g}\right)_{g \in G}$ in $\left(\left(K_{1}, K_{2}\right)\right)$ such that $d_{g} \longrightarrow d$. Then we have net $\left(k_{g}^{1}\right)_{\mathrm{g} \in \mathrm{G}}$ in $\mathrm{K}_{1}$, such that $\mathrm{d}_{\mathrm{g}} k_{g}^{1}$ $\in \mathrm{K}_{2}$, since $\mathrm{K}_{2}$ is compact, then there exists a subnet $\left(d_{g_{m}} k_{g_{m}}^{1}\right)$ of $\left(\mathrm{d}_{\mathrm{g}} k_{g}^{1}\right)$ such that $d_{g_{m}} k_{g_{m}}^{1} \longrightarrow k_{o}^{2}$, where $k_{o}^{2} \in \mathrm{K}_{2}$. But ( $k_{g_{m}}^{1}$ ) in $\mathrm{K}_{1}$ and $\mathrm{K}_{1}$ is compact, thus there is a point $k_{o}^{1} \in \mathrm{K}_{1}$ and a subnet of $k_{g_{m}}^{1}$ say itself such that $k_{g_{m}}^{1} \longrightarrow k_{o}^{1}$. Then $d_{g_{m}} k_{g_{m}}^{1} \longrightarrow d k_{o}^{1}=k_{o}^{2}$, which mean that $\mathrm{d} \in\left(\left(\mathrm{K}_{1}, \mathrm{~K}_{2}\right)\right)$, therefore $\left(\left(\mathrm{K}_{1}, \mathrm{~K}_{2}\right)\right)$ is closed in D.

3.3 Theorem: Let $\mathrm{X}$ be $\mathrm{D}-$ space and $\mathrm{x} \in \mathrm{X}$. Then $\mathrm{x} \in J(x)$ if and only if $\mathrm{x}$ has no thin neighborhood.

Proof: $\Rightarrow$ Let $\mathrm{x} \in J(x)$ and suppose that $\mathrm{x}$ has thin neighborhood, then there is a neighborhood $U$ of $x$ such that the set $((U, U))$ has compact closure .By hypothesis $\mathrm{x} \in$ $J(x)$, then there is a net $\left(\mathrm{d}_{\mathrm{g}}\right)_{\mathrm{g} \in \mathrm{G}}$ in D with $\mathrm{d}_{\mathrm{g}} \longrightarrow \infty$ and a net $\left(\chi_{\mathrm{g}}\right)_{\mathrm{g} \in \mathrm{G}}$ in $\mathrm{X}$ with $\chi_{\mathrm{g}} \longrightarrow$ $\mathrm{x}$ such that $\mathrm{d}_{\mathrm{g}} \chi_{\mathrm{g}} \longrightarrow \mathrm{x}$, since $\mathrm{U}$ is a neighborhood of $x$, thus there is $g_{0} \in G$ such that $\chi_{\mathrm{g}} \in \mathrm{U}$ and $\mathrm{d}_{\mathrm{g}} \chi_{\mathrm{g}} \in \mathrm{U}$ for each $\mathrm{g} \geq \mathrm{g}_{\mathrm{o}}$. Thus $\mathrm{d}_{\mathrm{g}} \in \overline{((\boldsymbol{U}, \boldsymbol{U}))}, \forall \mathrm{g} \geq \mathrm{g}_{\mathrm{o}}$, which is compact , and hence the net $\left(\mathrm{d}_{\mathrm{g}}\right)_{\mathrm{g} \in \mathrm{G}}$ must have a convergent subset, which is a contradiction, therefore $\mathrm{x}$ has no thin neighborhood.

Conversely: $\Leftarrow$ Let $\mathrm{x}$ has no thin neighborhood. We suppose that $\mathrm{x} \notin J(x)$, then by Theorem (2.5) there is an neighborhood $U$ of $x$ and a compact neighborhood $\mathrm{V}$ of e such that $\mathrm{dU} \cap \mathrm{U}=\phi$ for each $\mathrm{d} \notin \mathrm{V}$. In the other words, if $\mathrm{dU} \cap \mathrm{U} \neq \phi$, then $\mathrm{d} \in \mathrm{V}$, thus $((\mathrm{U}, \mathrm{U})) \subseteq \mathrm{V}$ which is compact, therefore $U$ is an thin neighborhood of $\mathrm{x}$, which is a contradiction, and hence $\mathrm{x} \in$ $J(x)$.

3.4 Theorem: Let $\mathrm{X}$ be a $\mathrm{D}$ - space and $\mathrm{x}$, $\mathrm{y}$ be two points of $\mathrm{X}$ such that $\mathrm{x}$ is periodic and $\mathrm{Dx}$ $\neq$ Dy. Then $\mathrm{y} \notin J \quad(x)$ if and only if there is a neighborhood $\mathrm{U}$ of $\mathrm{x}$, a neighborhood $\mathrm{W}$ of $\mathrm{y}$ and a compact neighborhood $\mathrm{V}$ of 0 , where 0 is the identity element of $\mathrm{D}$, such that $\mathrm{dU} \cap \mathrm{W}=$ $\phi$ for each $\mathrm{d} \notin \mathrm{V}$. 
Proof: $\Rightarrow$ Let $\mathrm{y} \notin J(x)$ such that $\mathrm{x}$ is periodic and $\gamma(\mathrm{x}) \neq \gamma(\mathrm{y})$. We suppose that the statement is not true, i.e., for each neighborhood $\mathrm{U}$ of $\mathrm{x}$, for each neighborhood $\mathrm{W}$ of $\mathrm{y}$ and each compact neighborhood $\mathrm{V}$ of 0 , there is $\mathrm{d} \notin \mathrm{V}$ and $\mathrm{dU} \cap \mathrm{W} \neq \phi$. We can choose $\left\{U_{n}\right\}_{n \in N}$ a sequence of an open neighborhood of $\mathrm{x}$ such that $\mathrm{U}_{\mathrm{n}+1} \subset \mathrm{U}_{\mathrm{n}} \subset \ldots$ and

$\bigcap_{n \in N} U_{n}=\{x\}$ and $\left\{\mathrm{W}_{\mathrm{n}}\right\}_{\mathrm{n} \in \mathrm{Z}}+$ be a sequence of an open neighborhood of $y$ such that $\mathrm{W}_{\mathrm{n}+1} \subset$

$\mathrm{W}_{\mathrm{n}} \subset \ldots$ and $\bigcap_{n \in N} W_{n}=\{y\}$, also we choose $\mathrm{V}$ as a compact neighborhood of 0 . Thus for each $n \in N$ there is $d_{n} \notin V$ and $d_{n} U_{n} \cap$ $\mathrm{W}_{\mathrm{n}} \neq \phi$ i.e., there is $\chi_{\mathrm{n}} \in \mathrm{U}_{\mathrm{n}}$ and $\mathrm{d}_{\mathrm{n}} \chi_{\mathrm{n}} \in \mathrm{W}_{\mathrm{n}}$, since $\bigcap_{n \in N} U_{n}=\{x\}$, then we have $\chi_{\mathrm{n}} \longrightarrow \mathrm{x}$ and $\mathrm{d}_{\mathrm{n}} \mathrm{\chi}_{\mathrm{n}} \longrightarrow \mathrm{y}$, by hypothesis $\mathrm{y} \notin J(x)$, then the sequence $\left(d_{n}\right)_{n \in N}$ has a convergent sub sequence,(say itself), i.e., there is a point $d \in D$ such that $\mathrm{d}_{\mathrm{n}} \longrightarrow \mathrm{d}$ thus $\mathrm{d}_{\mathrm{n}} \mathrm{x}_{\mathrm{n}} \longrightarrow \mathrm{dx}=\mathrm{y}$, which means that $\mathrm{Dx}=\mathrm{Dy}$, which is a contradiction. Thus the statement is true.

Conversely: $\Leftarrow$ Let the statement be true, suppose that $\mathrm{y} \in J(x)$. Then there is a net $\left(\mathrm{d}_{\mathrm{g}}\right)_{\mathrm{g} \in \mathrm{G}}$ in $\mathrm{G}$ with $\mathrm{d}_{\mathrm{g}} \longrightarrow \infty$ and a net $\left(\chi_{\mathrm{g}}\right)_{\mathrm{g} \in \mathrm{G}}$ in $\mathrm{X}$ with $\chi_{\mathrm{g}} \longrightarrow \mathrm{x}$ such that $\mathrm{d}_{\mathrm{g}} \chi_{\mathrm{g}} \longrightarrow \mathrm{y}$. By hypothesis, there exist neighborhood $U$ of $\mathrm{x}, \mathrm{W}$ is a neighborhood of $\mathrm{y}$ and $\mathrm{V}$ is a compact neighborhood of 0 such that $\mathrm{dU} \cap \mathrm{W}$ $=\phi$ for each $\mathrm{d} \notin \mathrm{V}$. Thus for $\mathrm{g}_{\mathrm{o}} \in \mathrm{G}$ we have $\chi_{\mathrm{g}} \in \mathrm{U}$ and $\mathrm{d}_{\mathrm{g}} \chi_{\mathrm{g}} \in \mathrm{W}$ for each $\mathrm{g} \geq \mathrm{g}_{\mathrm{o}}$, then $\mathrm{d}_{\mathrm{g}} \in \mathrm{V}$, which is compact, therefore the net $\left(\mathrm{d}_{\mathrm{g}}\right)_{\mathrm{g} \in \mathrm{G}}$ has convergent subnet, which is contradiction. Thus $\mathrm{y} \notin J(x)$.

3.5 Proposition: Let $X$ be a periodic D space. Then $J(x)=\phi$ for each $\mathrm{x} \in \mathrm{X}$ if and only if every pair of point $\mathrm{x}, \mathrm{y} \in \mathrm{X}$ such that $\mathrm{Dx} \neq$ Dy has relatively thin neighborhood.

Proof: $\Rightarrow$ Let $J(x)=\phi$ for each $\mathrm{x} \in \mathrm{X}$ and $\mathrm{y}$ be any point in $\mathrm{X}$. Thus $(\mathrm{y} \notin J(x))$. Then by Theorem (3.4) there is a neighborhood $U$ of $x$ and a neighborhood $\mathrm{W}$ of $\mathrm{y}$, and a compact neighborhood $\mathrm{V}$ of 0 such that $\mathrm{dU} \cap \mathrm{W}=\phi$ for each $\mathrm{d} \notin \mathrm{V}$, in the other words, $\mathrm{dU} \cap \mathrm{W} \neq \phi$ then $\mathrm{d} \in \mathrm{V}$ i.e., $((\mathrm{U}, \mathrm{W}))$ has compact closure, therefore $\mathrm{U}$ and $\mathrm{W}$ are relatively thin neighborhood.
Conversely: $\Leftarrow$ Let $\quad \mathrm{x}, \quad \mathrm{y} \in \mathrm{X}$. Then by hypothesis, there are relative thin neighborhood $\mathrm{U}$ of $\mathrm{x}$ and $\mathrm{W}$ of $\mathrm{y}$. Thus ((U, W)) has compact closure. If $\mathrm{V}_{1}=\overline{((U, W))}$ and $\mathrm{V}_{2}$ be a compact neighborhood of $\mathrm{D}_{\mathrm{x}}$, then $\mathrm{V}=\mathrm{V}_{1} \cup \mathrm{V}_{2}$ is a compact neighborhood of 0 and each $d \in V$, then $d U \cap W \neq \phi$ this means that $\mathrm{y} \notin J(x)$. But $\mathrm{x}$ and $\mathrm{y}$ are arbitrary, thus we have $J(x) \neq \phi$ for each $\mathrm{x} \in \mathrm{X}$.

3.6 Definition: A D - space $\mathrm{X}$ is said to be a Cartan D - space if every point in $\mathrm{X}$ has a thin neighborhood.

3.7 Proposition: If $\mathrm{X}$ is Cartan $\mathrm{D}$ - space, then each stabilizer $\mathrm{D}_{\mathrm{x}}$ of $\mathrm{D}$ is compact.

Proof: Let $\mathrm{x} \in \mathrm{X}$, then there exists a thin neighborhood $\mathrm{V}$ of $\mathrm{x}$. Clearly $\mathrm{D}_{\mathrm{x}}$ is closed in $\mathrm{D}$ and since $\mathrm{D}_{\mathrm{x}} \subseteq((\mathrm{V}, \mathrm{V}))$. Hence $\mathrm{D}_{\mathrm{x}}$ is compact. 3.8 Proposition: If $\mathrm{X}$ is an Cartan D-space, $\mathrm{H}$ is a closed $\mathrm{d}-\mathrm{sub}$ algebra of $\mathrm{D}$ and $\mathrm{Y}$ is an $\mathrm{H}$ invariant subspace of $\mathrm{X}$, then $\mathrm{Y}$ is a Cartan $\mathrm{H}$ space.

Proof: Since D is locally compact and $\mathrm{H}$ is a closed $\mathrm{d}$-sub algebra of $\mathrm{D}$, then $\mathrm{H}$ is locally compact. Now to show that $\mathrm{Y}$ is an $\mathrm{H}$-space. Define $\pi: \mathrm{H} \times \mathrm{Y} \rightarrow \mathrm{Y}$ such that $\quad \pi(\mathrm{h}, \mathrm{y})=$ hy for each $h \in H$ and $y \in Y$.

i) $\pi$ is continuous.

ii) $\pi(e, y)=e y=y$.

iii) $\pi\left(h_{1}, \pi\left(h_{2}, y\right)\right)=\pi\left(h_{1}, h_{2} y\right)=h_{1} h_{2} y$ $=\pi\left(\mathrm{h}_{1} \mathrm{~h}_{2}, \mathrm{y}\right)$.

Hence $\mathrm{Y}$ is an $\mathrm{H}$-space. At the present time we are going to prove that $\mathrm{Y}$ is Cartan. Let $y \in Y$. Then $y \in X$. Since $X$ is a Cartan D - space then $y$ has $U$ as a thin neighborhood in $\mathrm{X}$. Since $\mathrm{U} \cap \mathrm{Y}$ is a neighborhood of $y$ in $Y$. So $U \cap Y$ is a thin neighborhood of $y$ in $\mathrm{Y}$. Hence $\mathrm{Y}$ is an Cartan H-space.

3.9 Proposition: Let $\mathrm{X}$ and $\mathrm{Y}$ be $\mathrm{D}$ spaces. Then $\mathrm{X} \times \mathrm{Y}$ is a Cartan $\mathrm{D}$ - space if at least one of $\mathrm{X}$ or $\mathrm{Y}$ is Cartan.

Proof: At first we shall show that $\mathrm{X} \times \mathrm{Y}$ is a $D$ - space. Since $X$ is a $D$ - space, then $D$ acts on $X$ by $\pi_{1}: D \times X \rightarrow X$ such that $\pi_{1}$ $(d, x)=d x$ for each $d \in D$ and $x \in X$. Since $\mathrm{Y}$ is a $\mathrm{D}$ - space, then $\mathrm{D}$ acts on $\mathrm{Y}$ by $\pi$ ${ }_{2}: \mathrm{D} \times \mathrm{Y} \rightarrow \mathrm{Y}$ such that $\pi_{2}(\mathrm{~d}, \mathrm{y})=\mathrm{dy}$ for each $d \in D$ and $y \in Y$.Define $\pi: D \times X \times Y$ $\rightarrow \mathrm{X} \times \mathrm{Y}$ such that $\pi(\mathrm{d},(\mathrm{x}, \mathrm{y}))=\mathrm{d}(\mathrm{x}, \mathrm{y})=$ $(d x, d y)$ for each $d \in D, x \in X$ and $y \in Y$. 
i) $\pi$ is continuous .

ii) $\pi(e,(x, y))=e(x, y)=(e x, e y)=(x, y)$

iii) $\pi\left(\mathrm{d}_{1}, \pi\left(\mathrm{d}_{2},(\mathrm{x}, \mathrm{y})\right)=\pi\left(\mathrm{d}_{1}, \mathrm{~d}_{2}(\mathrm{x}, \mathrm{y})\right)\right.$ $=\mathrm{d}_{1} \mathrm{~d}_{2}(\mathrm{x}, \mathrm{y})=\left(\mathrm{d}_{1} \mathrm{~d}_{2} \quad \mathrm{x}, \quad \mathrm{d}_{1} \mathrm{~d}_{2} \quad \mathrm{y}\right)=\pi \quad\left(\mathrm{d}_{1} \mathrm{~d}_{2}\right.$ $,(\mathrm{x}, \mathrm{y}))$.Hence $\mathrm{X} \times \mathrm{Y}$ is a $\mathrm{D}-$ space. Now to prove that $\mathrm{X} \times \mathrm{Y}$ is Cartan. Let $(\mathrm{x}, \mathrm{y}) \in \mathrm{X} \times \mathrm{Y}$. Since $\mathrm{x} \in \mathrm{X}$ and $\mathrm{X}$ is Cartan, then there exists $\mathrm{U}$ a thin neighborhood of $x$. Then we get $U \times Y$ as a neighborhood of $(x, y)$ in $X \times Y$. Because we have $((U, U))=((U \times Y, U \times Y))$. So, $((\mathrm{U} \times \mathrm{Y}, \mathrm{U} \times \mathrm{Y}))$ is relatively compact , which means that $\mathrm{X} \times \mathrm{Y}$ is a Cartan $\mathrm{D}$ - space.

3.8 Theorem: Let $\mathrm{X}$ be a $\mathrm{D}$ - space. Then $\mathrm{X}$ is Cartan D - space if and only if

$J(x)$ for each $\mathrm{x} \in \mathrm{X}$.

Proof: $\Rightarrow$ If $X$ is a Cartan D - space. Let $x \in$ $J(x)$, then there is a net $\left(\mathrm{d}_{\mathrm{g}}\right)_{\mathrm{g} \in \mathrm{G}}$ in $\mathrm{D}$ with $\mathrm{d}_{\mathrm{g}}$ $\longrightarrow \infty$ and there is a net $\left(\chi_{\mathrm{g}}\right)_{\mathrm{g} \in \mathrm{G}}$ in $\mathrm{X}$ with $\chi_{\mathrm{g}}$ $\longrightarrow \mathrm{x}$ such that $\mathrm{d}_{\mathrm{g}} \chi_{\mathrm{g}} \longrightarrow \mathrm{x}$. Since $\mathrm{x} \in \mathrm{X}$ and $\mathrm{X}$ is a Cartan $\mathrm{D}$ - space, then $\mathrm{X}$ has an open neighborhood $U$ such that $((U, U))$ is relative thin. Then $((\mathrm{U}, \mathrm{U}))$ is relative compact. Thus there is $g \in \mathrm{G}, \chi_{\mathrm{g}}$ and $\mathrm{d}_{\mathrm{g}} \chi_{\mathrm{g}}$ are in U. So that $d_{g}$ is in $((U, U))$. Then $\left(d_{g}\right)_{g \in G}$ contains a convergent subnet, this is contradiction.

$\Leftarrow$ Suppose that $\mathrm{X}$ is not an Cartan D space. Then there is a point $\mathrm{x}$ in $\mathrm{X}$ such that $\mathrm{X}$ has no neighborhood relative thin. Since $X$ is completely regular, then by the point $\mathrm{x}$ has a sequence $\left\{U_{n}\right\}_{n \in Z^{+}}$of an open neighborhood such that $\mathrm{U}_{\mathrm{n}+1} \subset \quad \mathrm{U}_{\mathrm{n}} \subset \quad \ldots \quad$ and $\bigcap_{n \in Z^{+}} U_{n}=\{x\}$. Then $\left(\left(\mathrm{U}_{\mathrm{n}}, \mathrm{U}_{\mathrm{n}}\right)\right)$ is not relative thin. We can choose an open neighborhood $\mathrm{U}$ of 0 in $\mathrm{D}$ such that $\mathrm{D}_{\mathrm{x}} \subseteq \mathrm{U}$ and it is relative compact. Then there is a sequence $\left(d_{n}\right)_{n \in N}$ in $\left(\left(U_{n}, U_{n}\right)\right)-U$. Since $d_{n}$ in $D$ then there is a sequence $\left(\chi_{n}\right)_{n \in N}$ in $U_{n}$ such that $\mathrm{d}_{\mathrm{n}} \chi_{\mathrm{n}}$ is in $\mathrm{U}_{\mathrm{n}}$. Since $\bigcap_{n \in Z^{+}} \boldsymbol{U}_{n}=\{x\}$, then $\chi_{\mathrm{n}} \longrightarrow \mathrm{x}$ and $\mathrm{d}_{\mathrm{n}} \chi_{\mathrm{n}} \longrightarrow \mathrm{x}$. Since $\mathrm{x} \notin$ $J(x)$, then $\left(\mathrm{d}_{\mathrm{n}}\right)_{\mathrm{n} \in \mathrm{N}}$ has a convergent subsequence, say $\left(d_{n_{k}}\right)$ with $d_{n_{k}} \longrightarrow \mathrm{d}$. Thus $d_{n_{k}} \chi_{n_{k}} \longrightarrow \mathrm{x}, \chi_{n_{k}} \longrightarrow \mathrm{x}$ and $d_{n_{k}} \longrightarrow \mathrm{d}$, imply that $\mathrm{x}=\mathrm{xd}$. Hence $\mathrm{d}$ is in $\mathrm{D}_{\mathrm{x}}$ and hence $d_{n_{k}}$ is in $\mathrm{U}$ for large $\mathrm{n}_{\mathrm{k}}$ and this is contradiction.

\section{References}

[1] Bourbaki, N., Elements of Mathematics, "General Topology", Chapter 1- 4, Springer - Verlog, Heidelberg, NewYork, pairs, Tokyo, $2^{\text {nd }}$ Edition(1989).

[2] HU, Q. P.-LI, X.: On BCH-algebras, Math. Sem. Notes, Kobe Univ. 11 (1983), 313-320.

[3] HU, Q. P.-LI, X.: On proper BCHalgebras, Math. Japon. 30 (1985), 659661.

[4] IMAI, Y.-ISEKI, K.: On axiom systems of propositional calculi XIV, Proc. Japan Acad.Ser. A Math. Sci. 42 (1966), 19-22.

[5] ISEKI, K.: An algebra related with a propositional calculus, Proc. Japan Acad. Ser. A Math. Sci. 42 (1966), 2629.

[6] Joseph Neggers; Young Bae Jun; Hee Sik Kim: On d-ideals in d-algebras Mathematica Slovaca, Vol. 49 (1999), No. 3, 243--251

[7] Kelley, J.L.,"General Topology "VANNOS TRAND, PRINCETON.

[8] Navalagi, G.B., "Definition Bank in General Topology", (54) G (1991).

[9] NEGGERS, J.-KIM, H. S.: On dalgebras, Math. Slovaca 49 (1999), 1926.

[10] Sharma, J.N.," Topology" , Published by Krishna prakashan Mandir, Meerut (U.P), printed at Manoj printers, Meerut,(1977).

[11] Willard , S. ;"General Topology “ ; Addition, wesley publishing company ,Inc.(1970) . 


\section{نقاط الغاية و فضاء D - Dارتن}

$$
\text { جامعة المستنصرية حسين }
$$

$$
\text { قبيب كريم عبد الله }
$$

Habeebk.abdullah@uokufa.edu.iq

$$
\text { جامعة المستنصرية جلية }
$$

Haiderali@yahoo.com

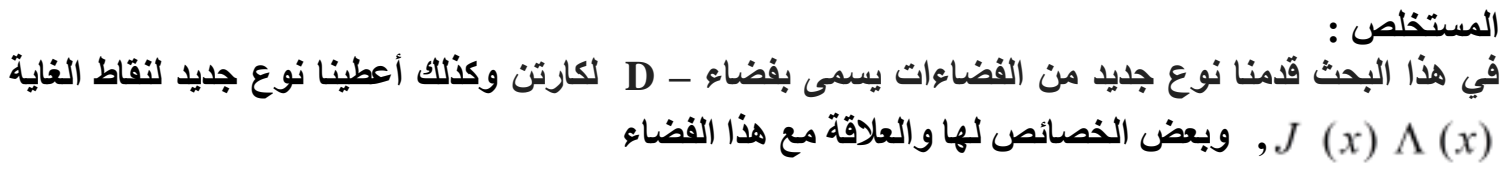

